\title{
A ATUAÇÃO DO EGRESSO DO CURSO TÉCNICO EM ADMINISTRAÇÃO NO MERCADO DE TRABALHO
}

\author{
Daniel Rocha Silva, Moises Luna Brandão, Fabricio Molica Mendonça, Jelson Luiz Dick \\ *E-mail: daniel.silva@ifnmg.edu.br \\ Centro Federal de Educação Tecnológica de Minas Gerais \\ DOI: 10.15628/rbept.2020.6394 \\ Artigo submetido em: out/2017 e aceito em mar/2020
}

\begin{abstract}
RESUMO
A oferta de cursos técnicos profissionalizantes viabiliza a inserção no mercado de trabalho de jovens e adultos e procura fomentar o desenvolvimento socioeconômico regional. Nesse sentido, o presente estudo objetivou identificar a situação de empregabilidade dos egressos do Curso Técnico em Administração. Foi realizada uma pesquisa de natureza quantitativa mediante questionário online aplicado aos egressos provenientes do cadastro de concluintes da Coordenação de Registros Escolares do Campus Pirapora do Instituto Federal do Norte de Minas Gerais. Responderam ao questionário 71 de um total de 147 egressos dos cursos nos anos de 2012 a 2015 , representando $48 \%$ da população. Foi identificado que a maioria dos egressos não está trabalhando na área do curso e uma pequena parte seguiu a vertificalização e está cursando o Bacharelado em Administração. A partir dos resultados, foi possível obter informações sobre a atuação do egresso do Curso Técnico em Administração no mercado de trabalho em Pirapora e região.
\end{abstract}

PALAVRAS-CHAVE: administração, técnico, egressos, mercado de trabalho.

\section{THE PERFORMANCE OF THE EGRESS OF THE TECHNICAL COURSE IN ADMINISTRATION IN THE JOB MARKET}

\begin{abstract}
The offer of technical vocational courses facilitates the insertion in the job market of young people and adults and tries to foment the regional socioeconomic development. In this sense the present study aimed to identify the employability situation of graduates of the Technical Course in Administration. A quantitative research was carried out through online questionnaires from the registry of graduates of the coordination of school records of the Pirapora Campus of the Federal Institute of the North of Minas Gerais. The questionnaire answered 71 out of a total of 147 course graduates in the years 2012 to 2015 , representing $48 \%$ of the population. It was identified that the vast majority of graduates are not working in the area of the course and a small part followed the vertification and is pursuing a baccalaureate degree in Business Administration. From the results it was possible to obtain the information about the performance of the egress from the Technical Course in Administration in the labor market in Pirapora and region.
\end{abstract}

KEYWORDS: administration, technical, graduates, job market. 


\section{INTRODUÇÃO}

Uma pesquisa com os egressos visa a contribuir para revelar a importância de determinado curso na formação profissional de uma determinada comunidade e a ofertar uma resposta com relação à eficiência do curso e seu papel de inclusão profissional. Dessa forma, verifica-se uma oportunidade de questionar se o propósito está sendo alcançado e a relevância dele na vida profissional do egresso. Segundo Silva, Finger e Vital (2008, p. 2), o "interesse por esse tema de pesquisa é decorrente da alta competitividade existente no mercado de trabalho, como mencionado, e da exigência de busca constante de aperfeiçoamento profissional".

O Curso Técnico em Administração vem atender à demanda de qualificação e formação básica dos estudantes, a fim de alavancar o comércio e a indústria regional, e gerar mão de obra qualificada, novas frentes de trabalho, novos empregos, melhoria na qualidade dos serviços prestados, sistematização na resolução dos problemas locais e elevação do potencial de empregabilidade, bem como contribuir para a formação cidadã dos educandos. De acordo com Silva et al. (2008, p. 3):

[...] o sistema educacional brasileiro oferece as seguintes opções para a continuidade dos estudos superiores: cursos sequenciais, com até dois anos de duração, e cursos de graduação, a maioria com quatro anos de duração, havendo, porém, cursos de formação tecnológica, com dois ou três anos de duração, e cursos com cinco ou seis anos, como os de engenharia e de medicina.

Diante desse cenário, é fundamental compreender a atuação do egresso no mercado de trabalho e como o Curso Técnico em Administração está envolvido em seu cotidiano. Pretendeu-se, portanto, caracterizar a atuação do egresso do Curso Técnico em Administração do Instituto Federal do Norte de Minas Gerais (IFNMG) Campus Pirapora - no mercado de trabalho. Como objetivos específicos, buscou-se identificar o ano de conclusão do curso; verificar a empregabilidade dos egressos do Curso Técnico em Administração, modalidade subsequente/concomitante, no período de 2012 a 2015; descrever a relação do último ou atual emprego com o Curso Técnico em Administração; e caracterizar o interesse do egresso em realizar um curso superior em Administração ou em outra área.

O mercado de trabalho anseia por profissionais capazes de aplicar os princípios da administração em suas operações, e os egressos do curso técnico em administração recebem formação para suprir essa necessidade. Contudo, alto índice de evasão e baixo aproveitamento percebido podem comprometer o cumprimento desse objetivo. Nesse contexto, percebeu-se a importância e relevância do presente trabalho, considerando ainda que "a educação tecnológica e o Ensino Técnico têm sido objeto de estudo em vários fóruns de debate e objeto de novas 
regulamentações no interior das políticas públicas atuais sobre educação tecnológica no País" (OLIVEIRA, 2000, p. 41).

A unidade de análise é o Campus Pirapora do Instituto Federal do Norte de Minas Gerais (IFNMG), que oferta o Curso Técnico em Administração subsequente/concomitante com entradas anuais de 40 alunos. $O$ curso tem duração de três semestres e forma um profissional técnico para atuar nas diversas linhas da área administrativa das empresas. O IFNMG é uma instituição de educação básica, profissional e superior, pluricurricular, multicampi e descentralizada, especializada na oferta de educação profissional e tecnológica nas diversas modalidades de ensino. O Campus Pirapora iniciou suas atividades no primeiro semestre de 2010 e fez parte do projeto de expansão da educação do IFNMG, que ocorreu em 2009, proporcionando qualificação pessoal e profissional para jovens e adultos estudantes da região (IFNMG, 2013).

O trabalho está organizado com o tópico sobre a metodologia utilizada, uma breve revisão teórica, os resultados e discussões, e as considerações finais além desta introdução.

\section{METODOLOGIA}

Esta foi uma pesquisa de abordagem quantitativa, utilizando survey, e foram pesquisados os egressos do Curso Técnico em Administração do período de 2012 a 2015, do IFNMG-Campus Pirapora, conforme dados levantados na Secretaria da instituição pesquisada, mediante questionário realizado e análise das respostas para averiguação da atuação do egresso no mercado de trabalho e a relação com o Curso Técnico em Administração.

O questionário alcançou $48 \%$ dos egressos e foi possível verificar a situação de empregabilidade destes. A pesquisa permite verificar quantitativamente a realidade desses egressos, não busca descrever a qualidade de seu emprego atual e pode indicar opções para aperfeiçoar o projeto pedagógico do curso.

A análise dos dados foi feita por meio dos gráficos gerados com as respostas dos egressos e verificada sua consistência, para que se pudesse obter uma resposta adequada às questões da pesquisa.

\section{REVISÃO TEÓRICA}

O Curso Técnico em Administração é fruto, em parte, da legislação educacional brasileira, que instituiu o ensino técnico profissional como parte fundamental da formação do jovem, objetivo em parte cumprido pelos institutos federais. De acordo com Cruz, Souza e Carneiro (2016, p. 86): 
[...] os Institutos Federais de Educação Profissional e Tecnológica - IF's têm adquirido importante responsabilidade na formação dos trabalhadores, principalmente, por fornecerem a base teórica e metodológica para o egresso atuar no mundo do trabalho. Assim, pesquisas com egressos se fazem importantes, por contribuírem com informações na perspectiva de avaliação dos cursos, apontando caminhos na possibilidade de garantir uma formação integral, não restrita aos aspectos técnicos e operacionais, mas que envolva conhecimentos de natureza política, cultural, econômica e social.

Essa concepção de formação técnica e tecnológica integraria a formação profissional e a flexibilização na oferta de programas que atendessem à demanda regional, sendo concebida e executada para fornecer mão de obra qualificada ao mercado de trabalho local (OLIVEIRA, 2000).

As especificidades necessárias para uma atuação no mercado de trabalho são, em sua maioria, concebidas na escola. Todavia, a empregabilidade dos egressos não está necessariamente relacionada ao curso realizado, gerando questionamentos sobre o tipo de oferta que está sendo feito. Conforme Oliveira (2000), na escola não se tem condição de oferecer treinamento para cada equipamento que está no mercado. Antes, porém, é fundamental formar o aluno para a vida.

De acordo com Cruz et al. (2013), as mudanças no mercado de trabalho exigem profissionais que sejam capazes de se adequarem e se adaptarem a diferentes cenários em constante mudança. Os cursos de formação profissional buscam, sobretudo, preparar os egressos para atuarem com instrumentos que supram tais necessidades do mercado e sem desvincular a sua formação do contexto macrossocial. Paralelamente a isso, espera-se que as políticas de formação sejam desenvolvidas com ações de incorporação do profissional formado no mercado de trabalho (BÓGUS, 2011).

Ainda na perspectiva de Cruz et al. (2013), o conceito de qualificação profissional não pode se restringir ao acúmulo de conhecimentos teóricos ou de natureza técnica e/ou operacional, pensadas de forma estanque. Ele deve contemplar uma formação humanística, artística, cultural e política; dessa forma, que não seja uma formação voltada apenas a atuação na área do curso concluído, mas que seja, além disso, uma contribuição social do curso, promovendo possibilidades contínuas de crescimento intelectual.

\section{RESULTADOS E DISCUSSÕES}

Este estudo utilizou-se de dados da Secretaria de Registros Escolares da instituição pesquisada. Por meio deles, chegou-se ao total de 147 egressos dos Cursos Técnicos em Administração do IFNMG-Campus Pirapora no período de 2012 a 2015. Após o envio do questionário a todos os egressos, este estudo obteve 
resposta ao questionário proposto de 71 egressos concluintes nos períodos demonstrados no Gráfico 1:

\section{Gráfico 1: Ano de Conclusão do Curso}

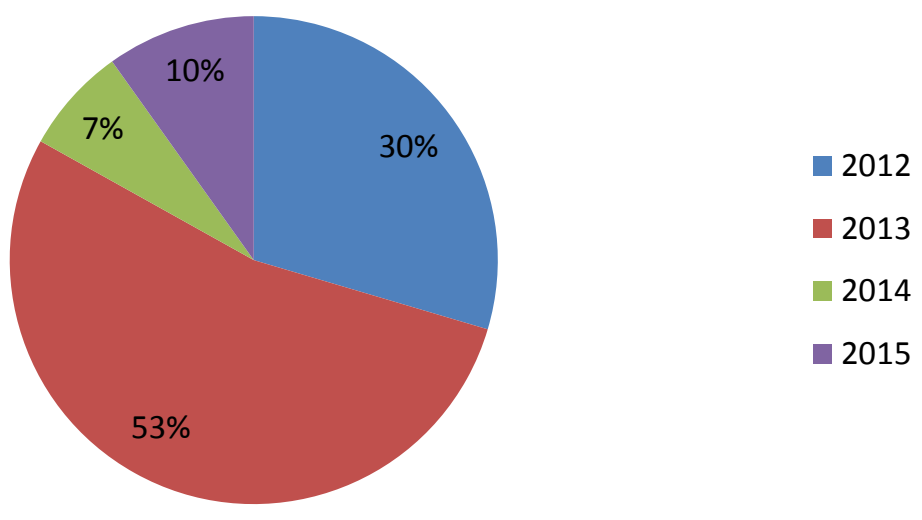

Fonte: Dados da pesquisa.

Conforme verificado na pesquisa, a maioria dos entrevistados concluiu o curso no ano de 2013, e os respondentes que disseram ter concluído o curso em 2012 foram 30\%. Aos concluintes dos últimos anos pesquisados, 2014 e 2015, houve pouco acesso e representam a minoria dos respondentes.

Quando perguntado sobre a situação de empregabilidade atual, as respostas são demonstradas no Gráfico 2:

\section{Gráfico 2: Atualmente}
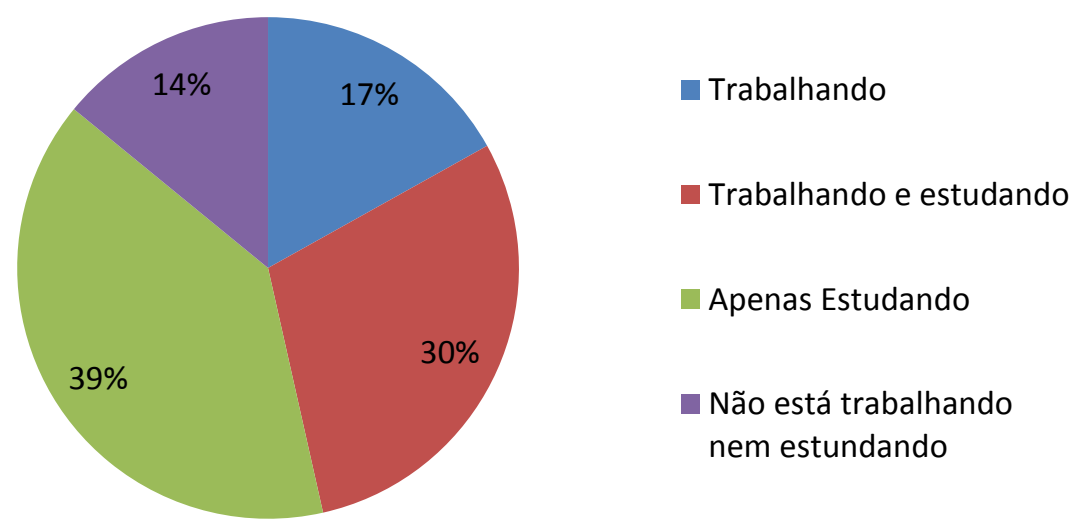

Fonte: Dados da pesquisa. 
A informação do Gráfico 2 pode representar o índice de desemprego entre os egressos do Curso Técnico em Administração já que 53\% responderam estarem apenas estudando ou nem estudando nem trabalhando. Esse dado vai ao encontro com a realidade da região, que, de acordo com o Instituto Brasileiro de Geografia e Estatística (IBGE), em 2016, apresentava o número de 24,9\% de pessoas ocupadas, desconsiderando crianças e aposentados. Entre os que trabalham, estudando ou não, o número é de $47 \%$. No entanto, nem sempre a formação implica necessariamente uma garantia de emprego. O gráfico evidencia essa realidade, mas propõe que o mercado de trabalho necessita, além da formação, de outras especificidades não abarcadas pela proposta pedagógica.

Com relação aos estudos, foi verificado se os egressos possuem outro curso técnico e ainda se estão cursando algum curso de graduação. As respostas são representadas nos Gráficos 3 e 4:

\section{Gráfico 3: Possui outro curso técnico}

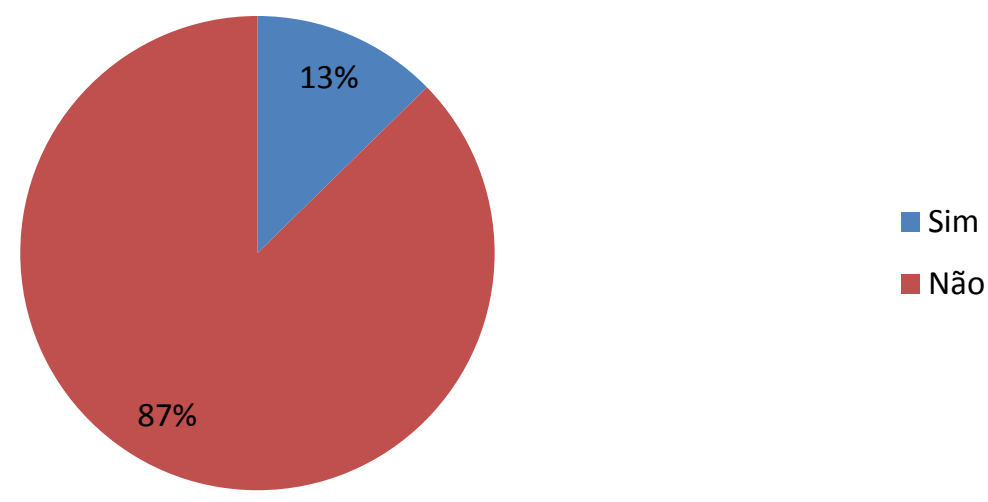

Fonte: Dados da pesquisa. 


\section{Gráfico 4: Cursa graduação}

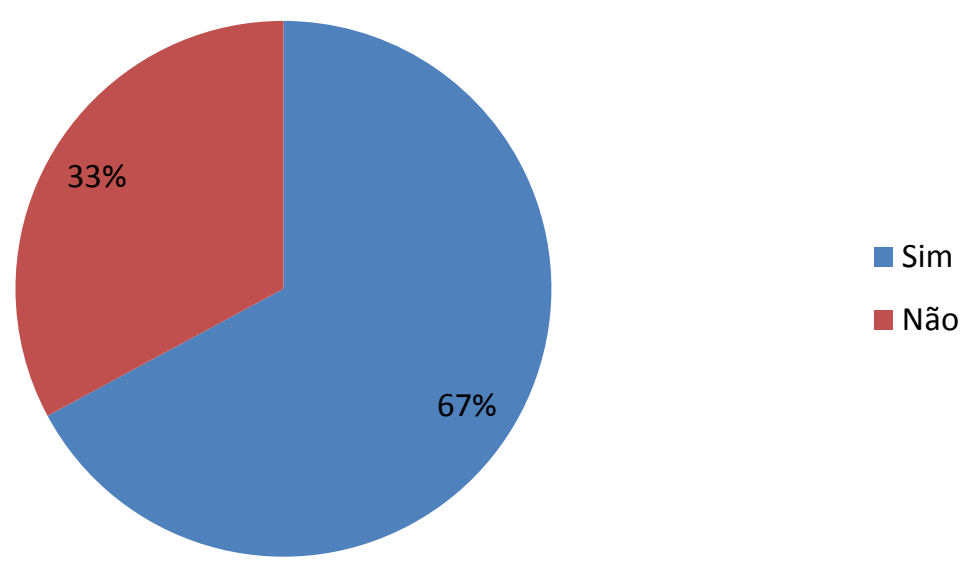

Fonte: Dados da pesquisa.

Em relação ao questionamento quanto à escolaridade e busca por qualificação técnica, percebeu-se que a maioria tem optado por buscar algum curso de graduação, e apenas $13 \%$ possuem algum outro curso técnico. Sobre o curso de graduação, $67 \%$ responderam estarem cursando. Entretanto, o número de egressos que cursam o Bacharelado em Administração é representado no Gráfico 5. Dos egressos do Curso Técnico em Administração, 23\% cursam Bacharelado em Administração, enquanto $44 \%$ cursam outras graduações. Há, ainda, os 33\% que não estão cursando graduação.

É importante ressaltar a baixa presença de outros cursos técnicos na formação dos respondentes, porém, mesmo assim, o número de egressos que buscam outras áreas para continuidade de sua formação é grande. Há, também, aqueles que não estão cursando graduação alguma, indicando, talvez, sua baixa capacidade de definir ou planejar uma carreira profissional. 


\section{Gráfico 5: Curso de graduação em andamento}

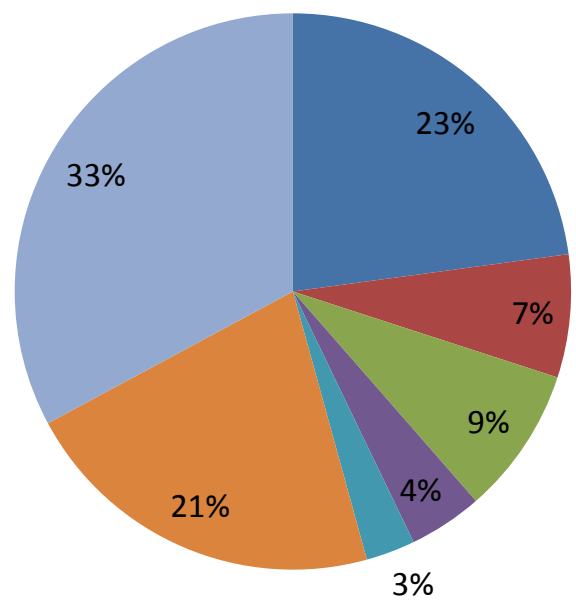

- Administração

Direito

Engenharia (cívil, mecatronica, florestal ou de alimentos)

- Medicina

- Sistemas de Informação

Fonte: Dados da pesquisa.

Para falar sobre a empregabilidade, é primordial demonstrar o vínculo empregatício atual dos egressos do Curso Técnico em Administração. No Gráfico 6, é representado o resultado da pergunta sobre o tipo de trabalho exercido pelos egressos no momento:

Gráfico 6: Vínculo Empregatício

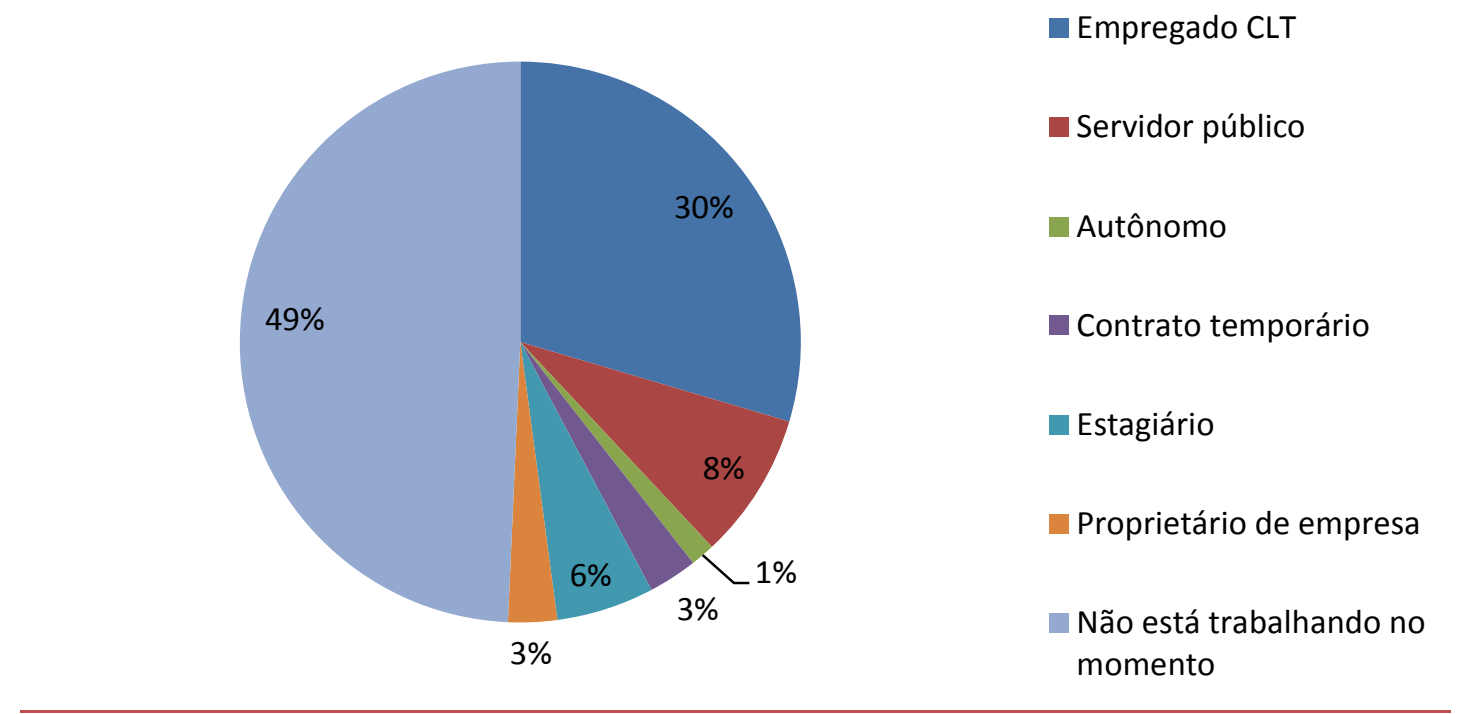

Fonte: Dados da pesquisa.

Diante dos resultados, é possível refletir quanto à empregabilidade dos egressos. Dos que responderam, $49 \%$ não possuem nenhum tipo de vínculo de emprego. Os egressos que trabalham somam $51 \%$ entre vínculos de empregados, 
estagiários, autônomos, com contrato temporário ou proprietário de um negócio próprio.

Todavia, percebeu-se, durante a pesquisa, que, entre aqueles que trabalham, o número dos que responderam que não trabalham na área de formação do curso técnico representa 55\% conforme o Gráfico 7:

\title{
Gráfico 7: Quanto tempo transcorreu da formatura até o primeiro emprego na área de formação
}

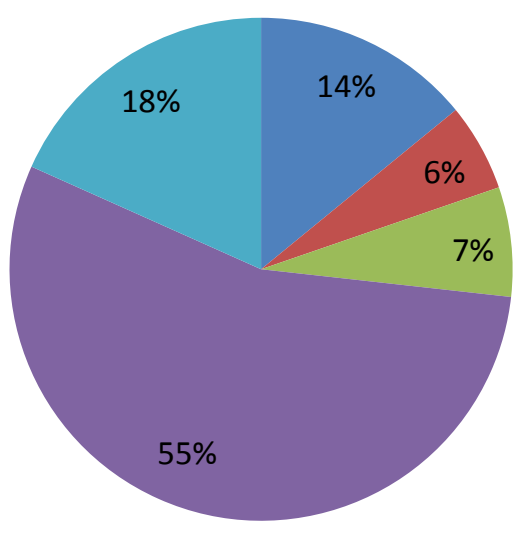

\author{
até 6 meses \\ de 6 meses a 1 ano \\ de 1 ano até 2 anos \\ não trabalho na área de \\ formação \\ - já trabalhava
}

Fonte: Dados da pesquisa.

Pôde ser evidenciado ainda que, após a conclusão do Curso Técnico em Administração, o egresso não conseguiu entrar no mercado de trabalho dentro de sua área de formação.

De acordo com os respondentes, $55 \%$ não trabalham na área de formação do curso técnico, o que pode deixar evidente que o Curso Técnico em Administração pouco contribuiu para sua empregabilidade na área.

Buscando entender ainda mais sobre a empregabilidade, a satisfação do respondente e a relação do Curso Técnico em Administração, foi questionado sobre a satisfação com a atividade profissional atualmente. O Gráfico 8 representa o seguinte resultado: 


\title{
Gráfico 8: Satisfação em relação à atividade profissional atualmente
}

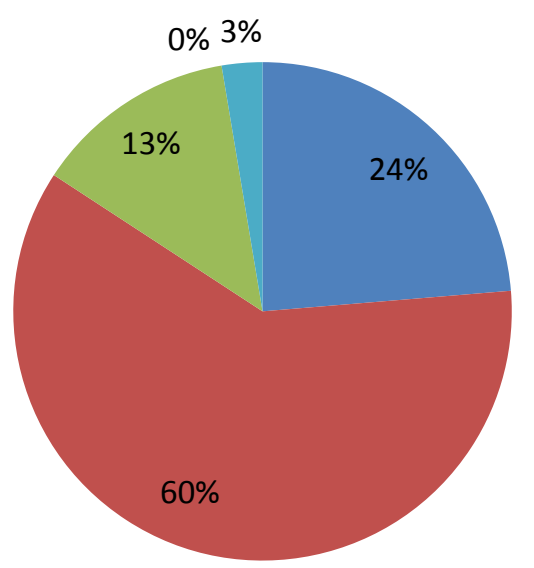

\author{
Muito satisfeito \\ Satisfeito \\ Indiferente \\ Insatisfeito \\ Muito insatisfeito
}

Fonte: Dados da pesquisa.

Considerando apenas aqueles que trabalham, constatou-se que $60 \%$ se dizem satisfeitos com a sua atual atividade profissional, $24 \%$ se dizem muito satisfeitos e apenas 3\% declararam-se muito insatisfeitos. Dessa forma, os dados evidenciam que, mesmo não atuando na área de formação, o fato de alcançarem uma formação técnica pôde fortalecer sua relação com o mercado.

Foi questionada a satisfação em relação ao Curso Técnico em Administração (Gráfico 9):

\section{Gráfico 9: Como foi o curso técnico em Administração}

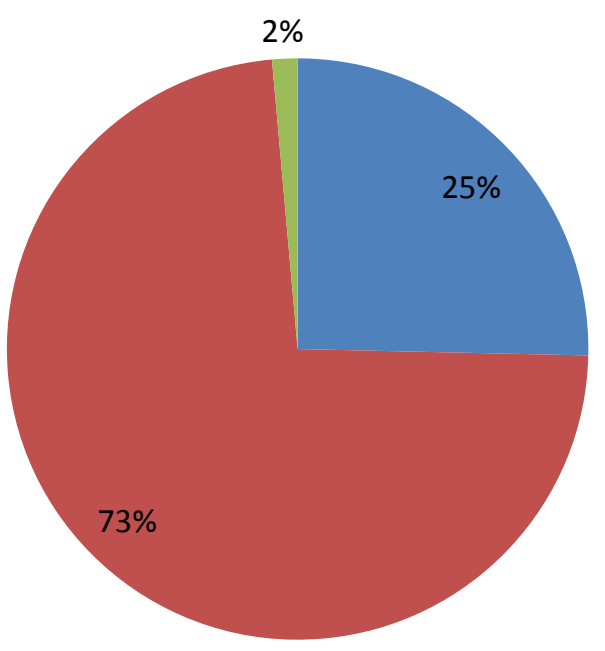

$$
\begin{aligned}
& \text { Superou as expectativas } \\
& \text { Atendeu as expectativas } \\
& \text { Não atendeu as expectativas }
\end{aligned}
$$

Fonte: Dados da pesquisa. 
Mediante essas respostas, os egressos deixam claro que o curso técnico cumpriu seu papel e atendeu às expectativas mesmo que sua conclusão não tenha influenciado tanto em sua empregabilidade.

\section{CONCLUSÃo}

Após verificar a atuação dos egressos do Curso Técnico em Administração do IFNMG/Campus Pirapora por meio de questionário respondido por 71 (48,3\%) egressos do campus, foi possível perceber algumas das dificuldades encontradas na conquista de seu espaço no mercado de trabalho.

Mesmo com algumas ofertas na área de atuação, fica claro que o Curso Técnico em Administração não é determinante para o egresso entrar no mercado de trabalho. Ainda que satisfeitos com o curso, acabam direcionando sua carreira para outras áreas de atuação.

É possível descrever o baixo número de egressos do curso técnico, que estão verticalizando sua formação acessando um curso de bacharelado na área. Ainda que seja considerável o número de egressos do curso técnico em curso superior, o grande número em cursos alheios ao de sua área de formação técnica deixa evidente a falta de aderência entre o curso técnico e as necessidades dos egressos.

Também é preciso verificar o perfil profissional que o mercado de trabalho atual está exigindo para exercer as funções técnicas relacionadas à área de gestão e negócios, bem como a melhor maneira de direcionar os egressos para sua preparação na busca por um espaço no mercado de trabalho.

Os dados desta análise apresentaram-se como um modelo sólido. Entretanto, sugere-se que em estudos futuros sejam incluídas outras variáveis com vistas a um melhor entendimento dos fatores que explicam a extensão da educação de um curso técnico no desenvolvimento regional local. Diante disso, fazem-se necessários mais estudos acerca da influência da qualificação técnica na empregabilidade, associados à melhoria de modos de vida e trabalho dos egressos, com o intuito de propor reformas educacionais mais amplas.

Considera-se fundamental que as instituições de formação estabeleçam uma relação participativa com a comunidade onde estão inseridas. Faz-se crucial uma discussão ampla sobre seus cursos e egressos, tanto para a mão de obra qualificada para o exercício profissional que o mercado de trabalho exige, bem como para o desenvolvimento socioeconômico regional, a fim de fomentar a aderência entre um curso técnico às necessidades dos egressos e às necessidades do mercado de trabalho e da sociedade. 


\section{REFERÊNCIAS}

BÓGUS, Cláudia Maria et al. Conhecendo egressos do curso técnico de Enfermagem do PROFAE. Revista da Escola de Enfermagem da USP, v. 45, n. 4, p. 945-952, 2011.

CRUZ, Keyla de Souza Lima; SOUSA, Antonia de Abreu; CARNEIRO, Isabel Magda Said Pierre. A QUALIFICAÇÃO PROFISSIONAL DOS EGRESSOS DO INSTITUTO FEDERAL DE EDUCAÇÃO, CIÊNCIA E TECNOLOGIA DO CEARÁ-IFCE. Revista Brasileira da Educação Profissional e Tecnológica, v. 1, n. 6, p. 85-94, 2016.

INSTITUTO BRASILEIRO DE GEOGRAFIA E ESTATÍTICA - IBGE. Cidades. Brasil, 2016. Disponível em: <https://cidades.ibge.gov.br/brasil/mg/pirapora/panorama>. Acesso em: 2 jul. 2018.

INSTITUTO FEDERAL DO NORTE DE MINAS GERAIS - IFNMG. Projeto pedagógico do curso técnico em administração. Pirapora: [s.n.], 2013.

OLIVEIRA, M. R. N. S. Mudanças no mundo do trabalho: Acertos e desacertos na proposta curricular para o Ensino Médio (Resolução CNE 03/98). Diferenças entre formação técnica e formação tecnológica. Educação e Sociedade, v. 21, n. 70, p. 40-62, 2000.

SILVA, Flora Moritz da; FINGER, Luciane; VITAL, Juliana Tatiane. Análise do Perfil Profissional dos Potenciais Formandos do Curso de Administração da Universidade Federal de Santa Catarina. 2008. 